\title{
Analysis of the Necessity to Develop the Forensic Accounting in
}

\section{China}

\author{
Xianghua Hao \\ Department of Graduate, Shandong Economic University, Ji’nan 250014, China \\ E-mail: haoxianghua@126.com
}

\begin{abstract}
Starting from the concept of the forensic accounting, by the discussions about the spreading false accounting information, the limitation of the laws and accounting, the deficiencies in the traditional auditing, and imperfect institution of the forensic accounting organization, the necessity to develop the forensic accounting in china is explained in this article.
\end{abstract}

Keywords: Forensic accounting, Law, Accounting, Auditing

China is in the term of economic transformation, and with the quick development of the economy and the continual enhancement of the comprehensive national strength, the accounting information is more and more important in the whole social and economic activity, and the amount of the civil action induced by the accounting information is increasing by the geometric series, which will all quicken the further integration of the legal domain and the accounting domain, and generate a new accounting domain, i.e. the forensic accounting.

The forensic accounting is the new accounting domain which was born in the west country of 1980s to adapt the development of the market economy and the perfection of the legal system. It is entrusted by the independent third party, and adopts certain procedures and methods to survey, compute, and analyze the management and financial items, and the part of economic loss, or the legal issues in the management in the conflict of economic benefit by the professional knowledge, and forms the forensic accounting report, and provides references for the court or the arbitration agency or the administration authority, and reduce or confirm legal responsibilities, or offers management advices. The forensic accounting is pushed by the development of the economic environment, and generated when the occupation change and the specialty development encounter bottleneck.

Aiming at the actuality of China, following aspects can be considered to review the necessity of developing the forensic accounting.

\section{The spreading false accounting information is the most essential cause to generate the forensic accounting}

Because of the false accounting information, the society and the economy suffers large loss, and the survival and development of the accounting industry is largely impacted, and investors' benefits are largely damaged, and the social public would largely doubt the social economic order. When the harm of the false accounting information develops to some extent, the lawsuit aiming at the false accounting information will occur, and it would make the accounting knowledge and the legal knowledge to be collided, and many situations which can not integrate completely would occur, and single accounting knowledge or single legal knowledge could not solve problems effectively. At present, China is in the term of economic transformation, and the amount of economic crime case and the sum of corruption increases obviously, and the embezzlement modes are more and more complex. When the court judges these cases, following issues must be confirmed. First, whether is the accounting information false? When judging this problem, professional accounting personnel and non-professional personnel always depend on different standards and obtain different conclusions. The references of professional personnel are the accounting rules and accounting systems, but the references of the non-professional personnel are the facts. The professional personnel pays more attention to whether the procedure of the accounting treatment is legal, and non-professional personnel would emphasize whether the result of accounting treatment is true, and both would obtain different judgment results. Second, does the false accounting information belong to intent, ordinary negligence, gross negligence, or deception? The intent and the deception need to undertake civil liability and criminal liability, and the negligence only undertakes the civil liability. According to different identification conclusions, the court would make different legal judgments. It is difficult to make exact judgment for the personnel with single legal knowledge or accounting knowledge. Third, what loss does the false accounting information bring to users? The losses suffered by the accounting information users when they make decisions 
according to false accounting information include the actual loss, the opportunity loss, and the holding loss, and it is also very difficult to identify these losses. The simple combination of accounting knowledge and legal knowledge could also achieve anticipated effect, therefore, people begin to realize the effective combination of these two kinds of knowledge with more theories and practices could effective solve problems, and fulfill the demand of the social and economic development.

\section{The limitations of laws and accounting limit the degree that they solve the problem effectively}

The science of law takes treating law regulations with high normalization as its main task, and mainly discusses the criterion meaning of the actual effect, the content of the criterion effect, and the judgment rule in the court's judgments. Under this thinking, traditional law science embodies the characters taking the legal relations analysis as the important measure, taking the value judgment as the instruct, and emphasizing the qualitative analysis, which also decides that in the judicial procedure, the space of the law is mainly limited in the liabilities such as behavior analysis and application. Many professional personnel including judge and lawyer are just legal experts, not accounting experts, so they can not exactly judge the problems of accounting. Legal personnel's experiences and knowledge have not been the connection point between the proof materials and the fact, so they have to transfer part of right to other professional personnel who would judge the professional technological problems, and forensic accounting just could play this role, and they could treat the proof materials by their own professional knowledge, and convert relative information into the contents which could be easily understood, and establish the bridge for judgers' reasoning.

For the science of accounting, the current accounting theory and practice of China have not completely been adapted with the legalization demand of the social and economic development, and many accounting personnel encountered similar mess more or less, i.e. in the accounting practice, some problems need to be judged by professional knowledge, but there are no specific examples in the accounting rule system could be quoted and learned, so they have to use their own experiences and the understanding of the rule idea to grasp the problem, and mistakes will often happen, and just because of this deficiency, someone could act audaciously in the so-called marginal land. Gradually, the modern social and economic phenomena become more and more complex, and the corresponding countermeasures must be proposed to treat them.

\section{Many deficiencies exist in traditional auditing}

In the condition of market economy, the social public has higher and higher anticipation for the auditing personnel. And the public requires that the auditing personnel could reflect relative situation of the continually difficult management of the enterprise. But because the accounting information is lagged behind the economic activity, the time limitation exists in the accounting reflecting the economic operations, and because modern faking and embezzlement technology is more and more advanced, registered accountants only could show their opinions about the justice and validity of the former financial report, and the identification function of the auditing has been largely limited. In addition, because of the limitation of the cost benefit principle and the special risk of the sampling technology, the registered accountants would face large uncertainty in the practice. The large gap exists in the public's higher anticipation for auditing personnel with the auditing result, and the registered accountants always can not depend on the auditing rule to defend themselves effectively.

The fraud auditing in the practice pays attention to the fraud skill, and doesn't want to solve legal problems, so many proofs obtained by the auditing could not connect with the demand of the court, and can not fulfill the demand of the lawsuit. In addition, even the auditing personnel discovers the fraud, what he can do is to further investigate the range of the essential test to confirm whether the above situation really exists, and provide corresponding advices, and inform the senior managers, and if the senior manager rejects to accept the advices, the auditing personnel could only give the auditing report with negative opinion or reserve opinion, or relieve the engagement. Comparing with independent auditing, the range of interior auditing is wider, but the interior auditing is still limited to discover the fraud because it could not ensure its independence completely in the practice and it will be limited by the implementation cost, and the interior character is obvious. The occurrence of forensic accounting could not only compensate the deficient service function of discovering fraud, but help accountants to enhance the reliability of the accounting information, reduce the uncertainty and illegibility, and become the communication bridge to reduce the gap between the public's anticipation for the accountants and auditing personnel with the actuality.

\section{There is no one professional institution which could provide the real service of forensic accounting}

In the supply actuality of forensic accounting of China, except the public security organs and some accounting firms with the forensic accounting identification qualification could provide the service of forensic accounting identification, there is not a special organization which could really provide the real forensic accounting service 
in China. Shanghai Forensic Accounting Identification Committee was concerned by the public, but for the service it could offered was mainly to "identify and judge the accounting auditing materials in the cases including the economic crime, economic dissension and part of civil and administrative disputes", which are basically same to traditional forensic identification range, and have not included most function of forensic accounting. In addition, for the consigning procedure of accepting cases, it "temporally accepts the consignments of judicial authorities and arbitration agency. The party, deputy, and paraclete could apply the judicial authorities and arbitration agencies handling the case, and then the judicial authorities and arbitration agencies put forward the identification consignments to the forensic accounting identification committee", which is same to the forensic identification personnel's responsibility. From this view, the occupation of the forensic accounting is still blank in China.

\section{Conclusions}

In the day that the market economy develops so quickly, the law and regulation system is the premise to standardize the accounting behaviors, and the combination of accounting and law will be closer. On the on hand, only the accounting knowledge has not exactly handling all accounting issues in the market economy, on the other hand, the standardization of the market economy by laws still needs to measure and record by the accounting. In large numbers of economic communications and economic trades, the amount of economic dissension case increases and these cases become more and more complex, which will largely strengthen the necessity to develop the forensic accounting. In the legal construction of China, the legal issues occurred in many accounting practice, or the legal affairs came down to the accounting knowledge, but because of the deficiency of theoretical instruction of the practice experience, these problems could be solved effectively. Sometimes, the investigations of economic cases would absorb accounting personnel, or depend on the accounting report offered by the registered accountants, but because those accounting personnel participating in the investigation usually lack in professional knowledge and experiences of forensic accounting, and the pertinence and validity of obtained financial proofs would be limited largely, and the evaluation of the economic loss might be improper, so the justice judgment of the court would often be influenced.

To sum up, the generation of the forensic accounting is closely related with the economic and legal background and the social demand, and the development and change of the economy and the society will be the core force to push the advance of the forensic accounting, but the limitations of law, accounting and auditing would limit the degree that they fulfill the demand of the public, and the supply of the forensic accounting in the practice is still deficient, which all decide that the forensic accounting should undertake the functions to deeply study the fraud rule, discover and govern the fraud, and establish the communication bridge among different relative subjects. At present, China should establish and develop the forensic accounting as soon as possible, and especially in the day that the legal construction of China is going to the mature, and the market legalization degree is continually being enhanced, and the market economy advances rapidly, we should evaluate the economic benefit conflicts from the angle of law and accounting to better promote the development of the economy and the perfection of the law.

\section{References}

Chu, Nan. (1999). Forensic Accounting: the Accountants in the New Century. China Finance. Dec, 9, 1999.

Gai, Di. (2003). Research of Relative Forensic Accounting Problems. Wuhan: Zhongnan University of Economics and Law.

Gai, Di \& Zhang, Jingfeng. (2003). Literature Review on Forensic Accounting. Accounting Research. No.5.

Li, Delin \& Chen, Muchun. (2000). Primary Study on the Standardization of the Forensic Accounting Identification System. Accounting Research, No.11.

Li, Ruoshan. (1999). Several Law Opinions Applying to Current Problems of Accounting in China. Accounting Research, No.6.

Pei, Li. (2003). Research of Relative Forensic Accounting Problems. Wuhan: Zhongnan University of Economics and Law.

Zhang, Rui \& Xie, Shunming. (2004). The New Area in Forensic Accounting: Provide Experts' Agreement to Security Civil Action. Accounting Research, No.5. 